\title{
Staining Cells with Extracts Prepared from Flowers of Bougainvillea X Buttiana.
}

\section{Journal of Histochemistry and Cell Biology@SJHR-Africa}

\author{
Paul Towet ${ }^{a, 1,2}$ \\ a Department of Health Sciences, University of Kisubi, \\ Kisubi, Uganda
}

\begin{abstract}
Background:
Staining is the application of dyes to specimens to impart colour to cells through a chemical reaction. The study aimed at finding plant extracts to stain human blood cells, stem sections of Amaranthus species, Gram-negative organisms such as Escherichia coli, and Gram-positive organisms such as Staphylococcus aureus.

Methodology:

Healthy mature flowers of Bougainvillea X buttiana and Amaranthus species plants were picked from gardens around the University of Kisubi. Bracts of Bougainvillea $X$ buttiana were separated from other flower parts and air-dried. Both negative and positive controls for cells were prepared.

Results:

White blood cells, platelets, and cells of Escherichia coli and Staphylococcus aureus did not stain under all treatments with the extracts while human red blood cells and stem sections of Amaranthus species stained under certain treatments with the extracts. The extracts were more successful in staining stem sections of Amaranthus species as compared to human red blood cells where staining occurred in very few circumstances. Stem sections of Amaranthus species required shorter durations to stain effectively while human red blood cells required longer durations to stain effectively.

Conclusion:

Extracts of the bracts of Bougainvillea $X$ buttiana can be experimented with various cells when their $\mathrm{pH}$ is neutral and alkaline.
\end{abstract}

\section{Introduction}

Staining is the application of dyes to specimens to impart colour to cells through a chemical reaction(Talaro et al.,2002). According to staining theory, acidic structures are stained by basic dyes while basic structures are stained by acidic dyes (Cheesebrough et al.,2006). Several parts of plants contain pigments some of which provide visual cues to pollinators and seed dispersers (Vargas et al.,2000). Such pigments are what previous researchers used to stain cells. In all studies, plant materials were dried to remove free water to concentrate their pigments. According to Vargas et al., (2014) plant pigments in the colour spectrum consisting of blue, red, pink, orange, and purple are anthocyanins and are more stable in conditions of low $\mathrm{pH}$, low temperature, and low light intensity. Previous researchers have tried to stain different types of cells such as renal biopsies (Raheem et al., 2015) and stem sections of Hibiscus(Deepali et al.,2014). In this study, Escherichia coli and Staphylococcus aureus cells stem sections of Amaranthus species and human blood cells were stained. Escherichia coli is Gram-negative bacteria, fastidious and lactose ferment-

\footnotetext{
${ }^{1}$ Corresponding author.

2E-mail: towetp@gmail.com
} 
ing while Staphylococcus aureus is Gram-positive, coagulase-positive, and catalase-positive. Amaranthus species are vascular plants common in Uganda and are used in schools as laboratory specimens for studying cells and tissues of higher plants. Human blood cells included red blood cells, platelets, and white blood cells. Raheem et al., (2015) used pure water extracts of Hibiscus sabdariffa to stain the cytoplasm and extracellular elements of tissue sections instead of eosin and the results were impressive. The disadvantage they noticed with their extracts was that a long duration of staining was required to obtain better results. Deepali et al., (2014) reported that aqueous extracts from plant materials stained the cytoplasm and organelles of Paramecium very effectively and from those observations, they estimated that aqueous extracts from plant materials are acidic. It was reported that extracts of Bougainvillea glabra were as good as safranin dye at staining histological specimens of plants as they were found to stain vascular bundles and xylem cells effectively but stained the cortex and medulla less effectively, Deepali et al., (2014) concluded their study by reporting that Bougainvillea glabra showed the best results for fungal and plant tissue staining whereas extracts from rose, hibiscus and henna were used instead of eosin and were very successful in staining animal tissues in combination with hematoxylin. Raheem et al., (2015) performed a study at Port Sudan Ahlia College; Port Sudan, Sudan in which they used Hibiscus sabdariffa extracts to stain renal histological sections as compared to Hematoxylin-Eosin routine stain. They stained paraffinembedded formalin-fixed renal sections using Hibiscus sabdariffa extracts at different concentrations and durations at room temperature. They got their best results when they used $5 \%$ Hibiscus sabdariffa solution for one hour and concluded that $5 \%$ Hibiscus sabdariffa solution could substitute eosin in the hematoxylin and eosin routine stain for histological sections.

Most conventional laboratory biological stains such as crystal violet and other synthetic chemicals pollute the environment (Ratna \& Padhi, 2012). These pose a challenge to laboratory waste management. There is growing interest worldwide to study and develop environmentally friendly biological stains using plant materials( Deepali et al.,2014). Some of the plant materials which have been used include Henna leaves, Madder stems, and flowers of Hibiscus and Bougainvillea glabra (Deepali et al., 2014). Raheem et al., (2015) did study in Sudan at Port Sudan University to stain biopsies with extracts of Hibiscus. At the time of performing this study, the researcher had not come across Ugandan work where extracts of plant materials have been used to stain cells. Floral extracts of Bougainvillea glabra were effective at staining Paramecium, vascular bundles, and biopsies Deepali et al., (2014). Flower extracts contain anthocyanin molecules which are natural colorants (Delgado, 2000) Anthocyanins range in colour from orange, pink, red, and violet to blue and are most conspicuous in flowers and fruits of vascular plants and are known to be harmless and water-soluble (Vargas, 2000). The study aimed to determine if acidified ethanol extracts prepared from bracts of Bougainvillea X buttiana can stain bacterial cells of Escherichia coli and Staphylococcus aureus, thick and thin films of human blood, and stem sections of Amaranthus species. The findings of this study make an important contribution to the promotion, development, and use of environmentally friendly biological stains prepared from the bracts of Bougainvillea $X$ buttiana. These findings can also guide other researchers in similar studies.

\section{Methodology}

\section{Specimen collection:}

Healthy mature flowers of Bougainvillea X buttiana and Amaranthus species plants were picked from gardens around the University of Kisubi. Presses of both Bougainvillea X buttiana and Amaranthus species were also prepared. Escherichia coli and Staphylococcus aureus were cultured on nutrient agar plates by subculturing from stock plates kept in the microbiology laboratory of the University of Kisubi. A venous blood sample was obtained from a participant who agreed to provide informed consent in writing.

\section{Drying the bracts of Bougainvillea $X$ buttiana}

Bracts of Bougainvillea $X$ buttiana were separated from other flower parts and air-dried on a sheet of polythene in a dark, cool, dry room in the teaching laboratories where the study was done. They were allowed to dry to a constant weight in five days.

\section{Preparation of extraction solvents}


Acidified (50\%) ethanol $(100 \mathrm{ml})$ was prepared by pipetting concentrated hydrochloric acid $(100 \mu \mathrm{l})$, followed by $52.63 \mathrm{ml}$ of ethanol (95\%) and made up to $100 \mathrm{ml}$ with distilled water. Acidified (absolute) ethanol $(100 \mathrm{ml})$ was prepared by pipetting concentrated hydrochloric acid (100 $\mu \mathrm{l})$ into a measuring cylinder followed by $99.9 \mathrm{ml}$ of absolute ethanol.

\section{Preparation of acidified ethanol extracts of the bracts of Bougainvillea $X$ buttiana}

The infusion technique was used to prepare acidified ethanol extracts of the bracts of Bougainvillea $X$ buttiana (Handa et al., 2008). Infusion separates soluble compounds from insoluble cellular marc. The principle of infusion is that the extraction solvent softens and breaks plant cell walls to release soluble phytochemicals (Handa, 2008).

Different concentrations of acidified ethanol extracts of the bracts of Bougainvillea $X$ buttiana were prepared to stain cells. The air-dried bracts of Bougainvillea $X$ buttiana were ground in a blender forming tiny particles to the extent of forming a powder. The different concentrations were prepared by infusing one $\mathrm{g}, 1.5 \mathrm{~g}$, five $\mathrm{g}$, and $10 \mathrm{~g}$ of air-dried bracts of Bougainvillea $X$ buttiana ground into very small parts in a blender using acidified $(50 \%)$ ethanol $(100 \mathrm{ml})$. The $\mathrm{pH}$ of the prepared extracts varied between 3.3 and 4.6.

Bougainvillea X buttiana bracts powder was weighed according to set values. The powder was transferred into extraction solvents $(100 \mathrm{ml})$ and stoppered. A piece of cotton wool was used to stopper each conical flask containing contents. The set-ups were placed in a dark, cool, and dry chamber and left to infuse for 1 hour (Sabarudin et al., 2006). Contents were separated using a strainer to obtain extracts in the beakers and leaving behind the marc in the strainer. The extracts were further purified, and the $\mathrm{pH}$ of the extracts was then determined. These were stored in a dark, cool, and dry chamber awaiting use in experiments. These procedures were conducted following the procedure of Sabarudin et al., (2016).

\section{Preparation of controls.}

The controls for Amaranthus species sections, smears of Escherichia coli and Staphylococcus aureus, and thin and thick films of blood were prepared.

\section{Negative control for Amaranthus species}

Amaranthus species negative control section was prepared by making a thin freehand transverse section of the stem using a razor blade. The sections were placed on a microscope slide and preserved with a drop of glycerol (30\%) using a Pasteur pipette. A coverslip was placed on the preparation and examined under a microscope using $5 \mathrm{X}$ and 10X objectives, respectively. The section was seen to be unstained but cells were visible though the level of contrast was low. The control slide was kept for further use.

\section{Positive control for Amaranthus species}

Amaranthus species positive control section was prepared by making a thin freehand transverse section of Amaranthus species using a razor blade. The section was immersed in a Petri dish containing methylene blue stain and left to stain for one minute. The section was transferred to a microscope slide where glycerol (30\%) was added. It was examined microscopically using the 5X and 10X objectives respectively. It was kept for further use.

\section{Negative control for Staphylococcus aureus}

Negative controls of Staphylococcus aureus were prepared by putting a drop of distilled water on each microscope slide using a Pasteur pipette. Staphylococcus aureus cells were picked from a colony of Staphylococcus aureus on a nutrient agar plate using an applicator stick and applied to the drop of distilled water on a microscope slide, mixed and spread to form a smear. The smear was air-dried on a flat horizontal surface on the laboratory bench. The smear was heat fixed using a Bunsen burner flame and left to cool after which immersion oil was added to the smear and it was examined using the immersion oil objective. The smear was seen to be unstained and no organisms were seen. After examination, the immersion oil was removed from the smear and the control smear was kept for further use.

\section{Positive control for Staphylococcus aureus}

The positive control for Staphylococcus aureus was made by preparing a microscope slide and adding a drop of distilled water to it. Cells of Staphylococcus aureus were picked from a nutrient agar plate using an applicator stick and applied on a microscope slide in a drop of distilled water, mixed, and spread to form smears. The smear was air-dried on a flat horizontal surface on the laboratory bench. The smear was heat 
fixed using a Bunsen burner flame and left to cool on a staining rack where it was flooded with methylene blue and left to stain for one minute(Cheesebrough et al., 2006). The smear was rinsed with distilled water, blot dried with tissue paper, and examined under a microscope using the immersion oil objective. The control smear was kept for further use.

\section{Negative control for Escherichia coli}

Negative controls of Escherichia coli were prepared by putting a drop of distilled water on each microscope slide using a Pasteur pipette. Escherichia coli cells were picked from a colony of Escherichia coli on a nutrient agar plate using an applicator stick and applied to the drop of distilled water on the slide, mixed, and spread to form a smear. The smear was air-dried on a flat horizontal surface on the laboratory bench. The smear was heat fixed using a Bunsen burner flame and left to cool after which immersion oil was added to the smear and it was examined using the immersion oil objective. After examination, the immersion oil was removed from the slide and it was kept for further use.

\section{Positive control for Escherichia coli}

The positive control for Escherichia coli was made by preparing a microscope slide and adding a drop of distilled water to it. Cells of Escherichia coli were picked from a nutrient agar plate using an applicator stick and applied on a microscope slide in a drop of distilled water, mixed, and spread to form smears. The smear was air-dried on a flat horizontal surface on the laboratory bench. The smear was heat fixed using a Bunsen burner flame and left to cool on a staining rack where it was flooded with methylene blue to stain for one minute (Cheesebrough et al., 2006). The smear was rinsed with distilled water, blot dried with tissue paper, and examined under a microscope using the immersion oil objective. The cells appeared as blue rods. Immersion oil was removed and the smear was kept for further use.

\section{Negative control for thin blood films}

The negative control for thin blood films was prepared by putting a drop of whole blood on one end of a microscope slide using a Pasteur pipette. Another microscope slide was used as a spreader to make a thin film (Cheesebrough et al., 2006. The thin blood film was air-dried on a flat horizontal surface on the laboratory bench. The air-dried film was fixed using absolute methanol for two minutes (Cheesebrough et al., 2006). The film was allowed to dry and immersion oil was applied to it and it was examined using the immersion oil objective of the microscope. The blood cells were observed to have not stained. Immersion oil was removed and the film was kept for further use.

\section{Positive control for thin blood films}

The positive control was prepared by putting a drop of whole blood on one end of a microscope slide using a Pasteur pipette. Another microscope slide was used as a spreader to make a thin film (Cheesebrough et al., 2006. The thin blood film was air-dried on a flat horizontal surface on the laboratory bench. The air-dried film was fixed in absolute methanol for two minutes (Cheesebrough et al., 2006) and stained with Field's stain B for 1 minute. The slide was rinsed in clean water and air-dried. Immersion oil was applied and the slide was observed under a microscope using the immersion oil objective. Red blood cells appeared pink. The control slide was kept for further use.

\section{Negative control for thick blood films}

The negative control for thick blood films was prepared by putting a drop of whole blood on a microscope slides using a Pasteur pipette and spread it to form a thick film. The film was thoroughly air-dried on a flat horizontal surface on the laboratory bench (Cheesebrough et al., 2006). The air-dried film was dipped in distilled water for five seconds, rinse in distilled water, and air-dried. Immersion oil was applied to the microscope slide, it was examined using the immersion oil objective and it was observed to have not stained. Immersion was removed and the slide was kept for further use.

\section{Positive control for thick blood films}

The positive control was prepared by putting a drop of whole blood on a microscope slide using a Pasteur pipette and spread it to form a thick film (Cheesebrough et al., 2006). The film was air-dried and stained with distilled water and air-dried on a microscope slide drying rack. Immersion oil was applied to dried films and they were observed under the microscope using the immersion oil objective along with both negative and positive control films. Subsequent thick blood films were stained following the above procedure. The subsequent blood films were stained with extracts prepared using $1.5 \mathrm{~g}$ of Bougainvillea 
$X$ buttiana bracts and $100 \mathrm{ml}$ acidified ethanol (50\%), 5g of Bougainvillea $X$ buttiana bracts and $100 \mathrm{ml}$ acidified ethanol (50\%), $10 \mathrm{~g}$ of Bougainvillea $X$ buttiana bracts and $100 \mathrm{ml}$ acidified ethanol (50\%) and $10 \mathrm{~g}$ of Bougainvillea $X$ buttiana bracts and $100 \mathrm{ml}$ acidified absolute ethanol.

\section{Staining cells with extracts of Bougainvillea $X$ buttiana}

Smears of Escherichia coli and Staphylococcus aureus, thick and thin films of blood, and transverse sections of stems of Amaranthus species were stained with extracts of Bougainvillea X buttiana. The extracts were prepared using acidified ethanol (50\%) and acidified absolute ethanol. Acidified absolute ethanol was used to prepare extracts only with $10 \mathrm{~g}$ of bracts of Bougainvillea $X$ buttiana which were processed to very small particles using a blender. While acidified ethanol (50\%) was used to prepare extracts with $1 \mathrm{~g}, 1.5 \mathrm{~g}$, $5 \mathrm{~g}$, and $10 \mathrm{~g}$ of bracts of Bougainvillea $\mathrm{X}$ buttiana which were processed to very small particles using a blender.

\section{Staining cells of Escherichia coli with extracts of Bougainvillea $X$ buttiana}

15 microscope slides were taken and a drop of distilled water put on each of them using a Pasteur pipette. Cells of Escherichia coli were picked using applicator sticks from colonies of Escherichia coli on a nutrient agar plate and transferred to the drop of distilled water on each microscope slide, mixed, and spread to form smears. The smears were air-dried on a flat horizontal surface on the working bench. The air-dried smears were heat-fixed using a Bunsen burner flame and divided into five groups with each group having three smears. The smears were put on a staining rack. The first, second, third, fourth, and fifth groups were stained with an extract prepared using one gram of air-dried Bougainvillea $X$ buttiana bracts and acidified ethanol (50\%) for one minute, two minutes, five minutes, 10 minutes and 20 minutes respectively. The staining extract was added from a Pasteur pipette. The smears were rinsed with distilled water, their backs wiped with blotting paper and they were air-dried on a microscope slide drying rack. Immersion oil was added to each smear and they were examined along with the positive and negative controls under the microscope using the immersion oil objective lens. Subsequent smears were prepared and stained following the above procedure. The subsequent smears of Escherichia coli were stained with extracts prepared using $1.5 \mathrm{~g}$ of Bougainvillea $X$ buttiana bracts and $100 \mathrm{ml}$ acidified ethanol (50\%), 5g of Bougainvillea $X$ buttiana bracts and $100 \mathrm{ml}$ acidified ethanol (50\%), $10 \mathrm{~g}$ of Bougainvillea $X$ buttiana bracts and $100 \mathrm{ml}$ acidified ethanol (50\%) and $10 \mathrm{~g}$ of Bougainvillea $X$ buttiana bracts and $100 \mathrm{ml}$ acidified absolute ethanol.

\section{Staining cells of Staphylococcus aureus with extracts of Bougainvillea X buttiana}

15 microscope slides were taken and a drop of distilled water was put on each of them using a Pasteur pipette. Cells of Staphylococcus aureus were picked using applicator sticks from colonies of Staphylococcus aureus on a nutrient agar plate and transferred to the drop of distilled water on each microscope slide, mixed, and spread to form smears. The smears were air-dried on a flat horizontal surface on the working bench. The air-dried smears were heat-fixed using a Bunsen burner flame and divided into five groups with each group having three smears. The smears were put on a staining rack. The first, second, third, fourth, and fifth group were stained with an extract prepared using one gram of air dried Bougainvillea $X$ buttiana bracts and acidified ethanol (50\%) for one minute, two minutes, five minutes, 10 minutes, and 20 minutes respectively. The staining extract was added from a Pasteur pipette. The smears were rinsed with distilled water, their backs wiped with blotting paper, and they were air-dried on a microscope slide drying rack. Immersion oil was added to each smear, and they were examined along with the positive and negative controls under the microscope using the immersion oil objective lens. The subsequent smears were stained following the above procedure. The subsequent smears of Staphylococcus aureus were stained with extracts prepared using $1.5 \mathrm{~g}$ of Bougainvillea $X$ buttiana bracts and $100 \mathrm{ml}$ acidified $50 \%$ ethanol, five grams of Bougainvillea $X$ buttiana bracts and $100 \mathrm{ml}$ acidified $50 \%$ ethanol, $10 \mathrm{~g}$ of Bougainvillea $X$ buttiana bracts and $100 \mathrm{ml}$ acidified $50 \%$ ethanol and $10 \mathrm{~g}$ of Bougainvillea $X$ buttiana bracts and $100 \mathrm{ml}$ acidified absolute ethanol.

\section{Staining thick films of human blood with extracts of Bougainvillea $X$ buttiana.}

15 microscope slides were taken and a drop of whole blood was added to each microscope slide using a Pasteur pipette and spread using the same Pasteur pipette to form thick blood films. The thick blood films were thoroughly air-dried on a flat horizontal surface on the laboratory bench and divided 
into five groups with each group having three films. The first, second, third, fourth, and fifth groups of thick blood films were stained with extracts in a Coplin jar prepared using one gram of air-dried bracts of Bougainvillea X buttiana bracts and $100 \mathrm{ml}$ of acidified ethanol (50\%) for one minute, five minutes, 10 minutes, 20 minutes, and 30 minutes respectively. The stained blood films were rinsed.

\section{Staining thin films of human blood with extracts of Bougainvillea $X$ buttiana.}

15 microscope slides were taken and thin films of human blood were made by putting a drop of whole blood on one end of each microscope slide using a Pasteur pipette. The thin blood films were made using other microscope slides as spreaders. The films were air-dried on a flat horizontal surface on the laboratory bench and divided into five groups with each group having three films. The air-dried films were fixed using absolute methanol for two minutes The first, second, third, fourth, and fifth groups of fixed thin blood films were immersed in a Coplin jar containing the extract prepared using one gram of air-dried bracts of Bougainvillea $X$ buttiana bracts in $100 \mathrm{ml}$ of acidified ethanol (50\%) and left to stain for one minute, five minutes, 10 minutes, 20 minutes and 30 minutes respectively. The stained blood films were rinsed with distilled water and air-dried on a microscope slide drying rack. Immersion oil was added to the stained thin blood films and observed using the immersion oil objective along with both negative and positive control films. Subsequent thin blood films were prepared and stained following the above procedure. The subsequent blood films were stained with extracts prepared using $1.5 \mathrm{~g}$ of Bougainvillea $X$ buttiana bracts and $100 \mathrm{ml}$ acidified ethanol (50\%), $5 \mathrm{~g}$ of Bougainvillea $X$ buttiana bracts and $100 \mathrm{ml}$ acidified ethanol (50\%), $10 \mathrm{~g}$ of Bougainvillea $X$ buttiana bracts and $100 \mathrm{ml}$ acidified ethanol (50\%) and $10 \mathrm{~g}$ of Bougainvillea X buttiana bracts and $100 \mathrm{ml}$ acidified absolute ethanol.

\section{Staining transverse sections of Amaranthus species with extracts of Bougainvillea $X$ buttiana .}

15 microscope slides and made 15 freehand transverse sections of stems of Amaranthus species using a razor blade. The sections were divided into five groups with each group having three sections. The first, second, third, fourth, and fifth groups of stem sections were put in a Petri dish containing the extract prepared using acidified ethanol (50\%) and one gram of air-dried bracts of Bougainvillea $X$ buttiana and left to stain for three minutes, nine minutes, 15 minutes, 21 minutes and 27 minutes respectively. The stained sections were each put on their respectively labeled microscope slide and a small drop of 30\% glycerol was applied to each stained section followed by a coverslip. The stained sections were then observed using the $X 5$ and $X 10$ microscope objectives along with the negative and positive control sections. The subsequent transverse sections of stems of Amaranthus species were stained following the above procedure. Subsequent transverse sections of Amaranthus species were stained with extracts prepared using $1.5 \mathrm{~g}$ of Bougainvillea $X$ buttiana bracts and $100 \mathrm{ml}$ acidified ethanol (50\%), $5 \mathrm{~g}$ of Bougainvillea $X$ buttiana bracts and $100 \mathrm{ml}$ acidified ethanol (50\%), $10 \mathrm{~g}$ of Bougainvillea $X$ buttiana bracts and $100 \mathrm{ml}$ acidified ethanol (50\%) and $10 \mathrm{~g}$ of Bougainvillea $X$ buttiana bracts and $100 \mathrm{ml}$ acidified absolute ethanol.

\section{RESULTS AND DISCUSSIONS:}

A positive sign (+) was used in the tables to indicate where staining was achieved and a negative sign (-) was used to indicate where staining was not achieved.

\section{DISCUSSION}

According to staining theory, acidic dyes stain basic components of cells while basic dyes stain acidic components of cells (Cheesebrough et al., 2006). Cells of Staphylococcus aureus and Escherichia coli did not stain with the acidified ethanol extracts of Bougainvillea $X$ buttiana. Bacterial cell walls are negatively charged due to a large number of negatively charged groups on their surface (Talaro et al., 2002) and for that reason, acidic staining solutions cannot penetrate bacterial cells to stain them. Acidic dyes are applied in negative staining of bacteria where they stain the background of bacterial cells(Talaro et al., 2002). In this study, the background of bacterial cells on the microscope glass slides did not stain. This can also be attributed to the methods used in the preparation and staining of smears of Escherichia coli and Staphylococcus aureus which were different from the standard protocol of negative staining for example rinsing the stained smear with distilled water, a step not done in negative staining. 
Table 1. showing the results of staining Escherichia coli with extracts prepared using $100 \mathrm{ml}$ of acidified ethanolic solvents of different concentrations and different masses of Bougainvillea X buttiana bracts powder.

\begin{tabular}{|c|c|c|c|}
\hline \multirow[t]{37}{*}{ Specimen } & $\begin{array}{l}\text { Mass of bracts and volume of solvent used to prepare } \\
\text { extracts }\end{array}$ & $\begin{array}{l}\text { Staining } \\
\text { duration }\end{array}$ & $\begin{array}{l}\text { Re- } \\
\text { sult }\end{array}$ \\
\hline & & 1 minute & - \\
\hline & & 1 minute & - \\
\hline & & 1 minute & - \\
\hline & & 2 minutes & - \\
\hline & & 2 minutes & - \\
\hline & & 2 minutes & - \\
\hline & & 5 minutes & - \\
\hline & 150\% ethanol & 5 minutes & - \\
\hline & & 5 minutes & - \\
\hline & & 10 minutes & - \\
\hline & & 10 minutes & - \\
\hline & & 10 minutes & - \\
\hline & & 20 minutes & - \\
\hline & & 20 minutes & - \\
\hline & & 20 minutes & - \\
\hline & & 1 minute & - \\
\hline & & 1 minute & - \\
\hline & & 1 minute & - \\
\hline & & 2 minutes & - \\
\hline & & 2 minutes & - \\
\hline & & 2 minutes & - \\
\hline & $1.5 \mathrm{~g}$ of Bougainvillea $X$ buttiana bracts powder/ $100 \mathrm{ml}$ of acidified & 5 minutes & - \\
\hline & 1.5 g or Bougainvilled $x$ buttiana bracts powaeri $100 \mathrm{mi}$ or acialitied & 5 minutes & - \\
\hline & & 5 minutes & - \\
\hline & & 10 minutes & - \\
\hline & & 10 minutes & - \\
\hline & & 10 minutes & - \\
\hline & & 20 minutes & - \\
\hline & & 20 minutes & - \\
\hline & & 20 minutes & - \\
\hline & & 1 minute & - \\
\hline & & 1 minute & - \\
\hline & & 1 minute & - \\
\hline & & 2 minutes & - \\
\hline & & 2 minutes & - \\
\hline & & 2 minutes & - \\
\hline \multirow{17}{*}{$\begin{array}{l}\text { Escherichia } \\
\text { coli }\end{array}$} & $5 \mathrm{~g}$ of Bougainvillea $X$ buttiana bracts powder/ $100 \mathrm{ml}$ of acidified & 5 minutes & - \\
\hline & 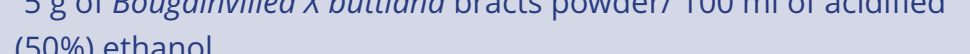 & 5 minutes & - \\
\hline & & 5 minutes & - \\
\hline & & 10 minutes & - \\
\hline & & 10 minutes & - \\
\hline & & 10 minutes & - \\
\hline & & 20 minutes & - \\
\hline & & 20 minutes & - \\
\hline & & 20 minutes & - \\
\hline & & 1 minute & - \\
\hline & & 1 minute & - \\
\hline & & 1 minute & - \\
\hline & & 2 minutes & - \\
\hline & & 2 minutes & - \\
\hline & & 2 minutes & - \\
\hline & & 5 minutes & - \\
\hline & $(50 \%)$ ethanol & 5 minutes & - \\
\hline
\end{tabular}


Table 2. Showing the results of staining Staphylococcus aureus with extracts prepared using $100 \mathrm{ml}$ of acidified ethanolic solvents of different concentrations and different masses of Bougainvillea X buttiana bracts powder.

\begin{tabular}{|c|c|c|c|}
\hline \multirow[t]{37}{*}{$\begin{array}{l}\text { Speci- } \\
\text { men }\end{array}$} & \multirow[t]{7}{*}{$\begin{array}{l}\text { Mass of bracts and volume of solvent used to prepare } \\
\text { extracts }\end{array}$} & $\begin{array}{l}\text { Staining } \\
\text { duration }\end{array}$ & $\begin{array}{l}\text { Re- } \\
\text { sult }\end{array}$ \\
\hline & & 1 minute & - \\
\hline & & 1 minute & - \\
\hline & & 1 minute & - \\
\hline & & 2 minutes & - \\
\hline & & 2 minutes & - \\
\hline & & 2 minutes & - \\
\hline & \multirow{15}{*}{$\begin{array}{l}1 \mathrm{~g} \text { of Bougainvillea X buttiana bracts powder/ } 100 \mathrm{ml} \text { of acidified } \\
(50 \%) \text { ethanol }\end{array}$} & 5 minutes & - \\
\hline & & 5 minutes & - \\
\hline & & 5 minutes & - \\
\hline & & 10 minutes & - \\
\hline & & 10 minutes & - \\
\hline & & 10 minutes & - \\
\hline & & 20 minutes & - \\
\hline & & 20 minutes & - \\
\hline & & 20 minutes & - \\
\hline & & 1 minute & - \\
\hline & & 1 minute & - \\
\hline & & 1 minute & - \\
\hline & & 2 minutes & - \\
\hline & & 2 minutes & - \\
\hline & & 2 minutes & - \\
\hline & \multirow{15}{*}{$\begin{array}{l}1.5 \mathrm{~g} \text { of Bougainvillea } X \text { buttiana bracts powder/ } 100 \mathrm{ml} \text { of acidified } \\
(50 \%) \text { ethanol }\end{array}$} & 5 minutes & - \\
\hline & & 5 minutes & - \\
\hline & & 5 minutes & - \\
\hline & & 10 minutes & - \\
\hline & & 10 minutes & - \\
\hline & & 10 minutes & - \\
\hline & & 20 minutes & - \\
\hline & & 20 minutes & - \\
\hline & & 20 minutes & - \\
\hline & & 1 minute & - \\
\hline & & 1 minute & - \\
\hline & & 1 minute & - \\
\hline & & 2 minutes & - \\
\hline & & 2 minutes & - \\
\hline & & 2 minutes & - \\
\hline \multirow{17}{*}{$\begin{array}{l}\text { Staphylo- } \\
\text { coccus } \\
\text { aureus }\end{array}$} & \multirow{15}{*}{$\begin{array}{l}5 \mathrm{~g} \text { of Bougainvillea } X \text { buttiana bracts powder/ } 100 \mathrm{ml} \text { of acidified } \\
(50 \%) \text { ethanol }\end{array}$} & 5 minutes & - \\
\hline & & 5 minutes & - \\
\hline & & 5 minutes & - \\
\hline & & 10 minutes & - \\
\hline & & 10 minutes & - \\
\hline & & 10 minutes & - \\
\hline & & 20 minutes & - \\
\hline & & 20 minutes & - \\
\hline & & 20 minutes & - \\
\hline & & 1 minute & - \\
\hline & & 1 minute & - \\
\hline & & 1 minute & - \\
\hline & & 2 minutes & - \\
\hline & & 2 minutes & - \\
\hline & & 2 minutes & - \\
\hline & \multirow{2}{*}{$\begin{array}{l}10 \mathrm{~g} \text { of Bougainvillea } X \text { buttiana bracts powder/ } 100 \mathrm{ml} \text { of acidified } \\
(50 \%) \text { ethanol }\end{array}$} & 5 minutes & - \\
\hline & & 5 minutes & - \\
\hline
\end{tabular}


Table 3. showing the results of staining human thick blood films with extracts prepared using $100 \mathrm{ml}$ of acidified ethanolic solvents of different concentrations and different masses of Bougainvillea X buttiana bracts powder.

$\begin{aligned} & \text { Speci- } \\ & \text { men } \\ & \text { extracts }\end{aligned}$
$1 \mathrm{~g}$ of Bougainvillea X buttiana bracts powder/ $100 \mathrm{ml}$ of acidified
(50\%) ethanol
$1.5 \mathrm{~g}$ of Bougainvillea X buttiana bracts powder/ $100 \mathrm{ml}$ of acidified
(50\%) ethanol

Thick films of human blood
$5 \mathrm{~g}$ of Bougainvillea $X$ buttiana bracts powder/ $100 \mathrm{ml}$ of acidified (50\%) ethanol

\section{Staining}

duration

1 minute

1 minute

1 minute

5 minutes

5 minutes

5 minutes

10 minutes

10 minutes

10 minutes

20 minutes

20 minutes

20 minutes

30 minutes

30 minutes

30 minutes

1 minute

1 minute

1 minute

5 minutes

5 minutes

5 minutes

10 minutes

10 minutes

10 minutes

20 minutes

20 minutes

20 minutes

30 minutes

30 minutes

30 minutes

1 minute

1 minute

1 minute

5 minutes

5 minutes

10 minutes

10 minutes

10 minutes

20 minutes

20 minutes

20 minutes

30 minutes

30 minutes

30 minutes

1 minute

1 minute

1 minute

5 minutes

5 minutes

5 minutes

10 minutes

10 minutes

$(50 \%)$ ethanol
$\mathrm{Re}$ -

sult

$-$

$-$

$-$

$-$

$-$

$-$

$-$

$-$

$-$

$-$

$-$

$-$

$-$

$-$

$-$

$-$

$-$

$-$

$-$

$-$

$-$

$-$

$-$

$-$

$-$

$-$

$-$

$-$

$-$ 
Table 4. showing the results of staining human thin blood films with extracts prepared using $100 \mathrm{ml}$ of acidified ethanolic solvents of different concentrations and different masses of Bougainvillea X buttiana bracts powder.

\begin{tabular}{|c|c|}
\hline $\begin{array}{l}\text { Speci- } \\
\text { men }\end{array}$ & $\begin{array}{l}\text { Mass of bracts and volume of solvent used to prepare } \\
\text { extracts }\end{array}$ \\
\hline & $\begin{array}{l}1 \mathrm{~g} \text { of Bougainvillea X buttiana bracts powder/ } 100 \mathrm{ml} \text { of acidified } \\
(50 \%) \text { ethanol }\end{array}$ \\
\hline & $\begin{array}{l}\text { 1.5g Bougainvillea X buttiana bracts powder/ } 100 \mathrm{ml} \text { of acidified } \\
(50 \%) \text { ethanol }\end{array}$ \\
\hline $\begin{array}{l}\text { Thin films } \\
\text { of human } \\
\text { blood }\end{array}$ & $\begin{array}{l}5 \mathrm{~g} \text { Bougainvillea } X \text { buttiana bracts powder/ } 100 \mathrm{ml} \text { of acidified }(50 \%) \\
\text { ethanol }\end{array}$ \\
\hline
\end{tabular}

\section{Staining}

duration

1 minute

1 minute

1 minute

5 minutes

5 minutes

5 minutes

10 minutes

10 minutes

10 minutes

20 minutes

20 minutes

20 minutes

30 minutes

30 minutes

30 minutes

1 minute

1 minute

1 minute

5 minutes

5 minutes

5 minutes

10 minutes

10 minutes

10 minutes

20 minutes

20 minutes

20 minutes

30 minutes

30 minutes

30 minutes

1 minute

1 minute

5 minutes

5 minutes

5 minutes

10 minutes

10 minutes

10 minutes

20 minutes

20 minutes

20 minutes

30 minutes

30 minutes

30 minutes

1 minute

1 minute

1 minute

5 minutes

5 minutes

5 minutes

10 minutes

10 minutes
1 minute

Result -

$-$

$-$

$-$

$-$

$-$

$-$

$-$

$-$

$-$

$-$

$-$

$-$

$-$

$-$

$-$

$-$ 
Table 5. showing the results of staining transverse sections of Amaranthus species with extracts prepared using $100 \mathrm{ml}$ of acidified ethanolic solvents of different concentrations and different masses of Bougainvillea X buttiana bracts powder.

\begin{tabular}{|c|c|c|c|}
\hline \multirow[t]{35}{*}{$\begin{array}{l}\text { Speci- } \\
\text { men }\end{array}$} & \multirow[t]{7}{*}{$\begin{array}{l}\text { Mass of bracts and volume of solvent used to prepare } \\
\text { extracts }\end{array}$} & $\begin{array}{l}\text { Staining } \\
\text { duration }\end{array}$ & $\begin{array}{l}\text { Re- } \\
\text { sult }\end{array}$ \\
\hline & & 3 minute & - \\
\hline & & 3 minute & - \\
\hline & & 3 minute & - \\
\hline & & 9 minutes & - \\
\hline & & 9 minutes & - \\
\hline & & 9 minutes & - \\
\hline & \multirow{15}{*}{$\begin{array}{l}\text { 1g of Bougainvillea X buttiana bracts powder/ } 100 \mathrm{ml} \text { of acidified } \\
(50 \%) \text { ethanol }\end{array}$} & 15 minutes & - \\
\hline & & 15 minutes & - \\
\hline & & 15 minutes & - \\
\hline & & 21 minutes & - \\
\hline & & 21 minutes & - \\
\hline & & 21 minutes & - \\
\hline & & 27 minutes & - \\
\hline & & 27 minutes & - \\
\hline & & 27 minutes & - \\
\hline & & 3 minute & - \\
\hline & & 3 minute & - \\
\hline & & 3 minute & - \\
\hline & & 9 minutes & - \\
\hline & & 9 minutes & - \\
\hline & & 9 minutes & - \\
\hline & \multirow{15}{*}{$\begin{array}{l}1.5 \mathrm{~g} \text { Bougainvillea } X \text { buttiana bracts powder/ } 100 \mathrm{ml} \text { of acidified } \\
(50 \%) \text { ethanol }\end{array}$} & 15 minutes & - \\
\hline & & 15 minutes & - \\
\hline & & 15 minutes & - \\
\hline & & 21 minutes & - \\
\hline & & 21 minutes & - \\
\hline & & 21 minutes & - \\
\hline & & 27 minutes & - \\
\hline & & 27 minutes & - \\
\hline & & 27 minutes & - \\
\hline & & 3 minute & + \\
\hline & & 3 minutes & + \\
\hline & & 9 minutes & + \\
\hline & & 9 minutes & + \\
\hline \multirow{18}{*}{$\begin{array}{l}\text { Transverse } \\
\text { stem } \\
\text { sections of } \\
\text { Amaran- } \\
\text { thus } \\
\text { species }\end{array}$} & & 9 minutes & + \\
\hline & & 15 minutes & + \\
\hline & \multirow{14}{*}{$\begin{array}{l}5 \mathrm{~g} \text { Bougainvillea X buttiana bracts powder/ } 100 \mathrm{ml} \text { of acidified (50\%) } \\
\text { ethanol }\end{array}$} & 15 minutes & + \\
\hline & & 15 minutes & + \\
\hline & & 21 minutes & + \\
\hline & & 21 minutes & + \\
\hline & & 21 minutes & + \\
\hline & & 27 minutes & + \\
\hline & & 27 minutes & + \\
\hline & & 27 minutes & + \\
\hline & & 3 minute & + \\
\hline & & 3 minute & + \\
\hline & & 3 minute & + \\
\hline & & 9 minutes & + \\
\hline & & 9 minutes & + \\
\hline & & 9 minutes & + \\
\hline & \multirow{2}{*}{$\begin{array}{l}\text { 10g Bougainvillea X buttiana bracts powder/ } 100 \mathrm{ml} \text { of acidified } \\
(50 \%) \text { ethanol }\end{array}$} & 15 minutes & + \\
\hline & & 15 minutes & + \\
\hline
\end{tabular}




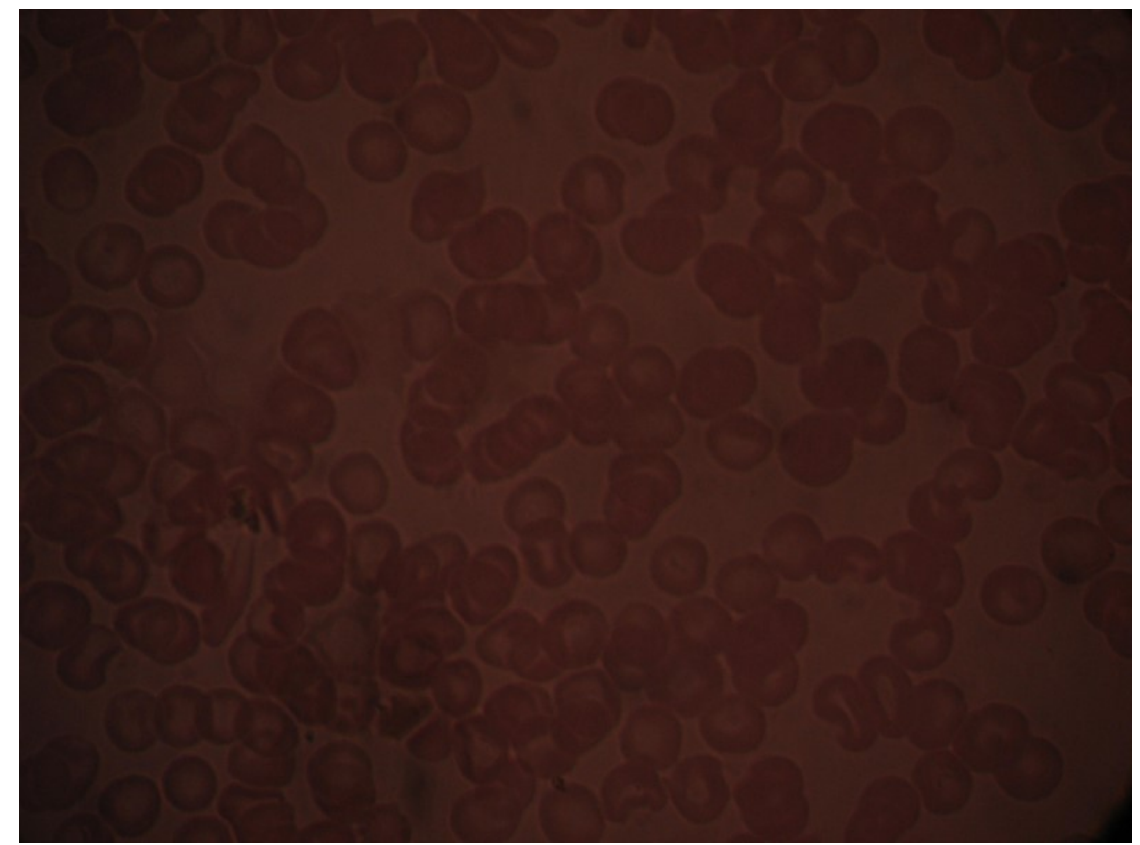

Figure 1. Showing red blood cells in a thin film of human blood stained with Bougainvillea X buttiana bract extract

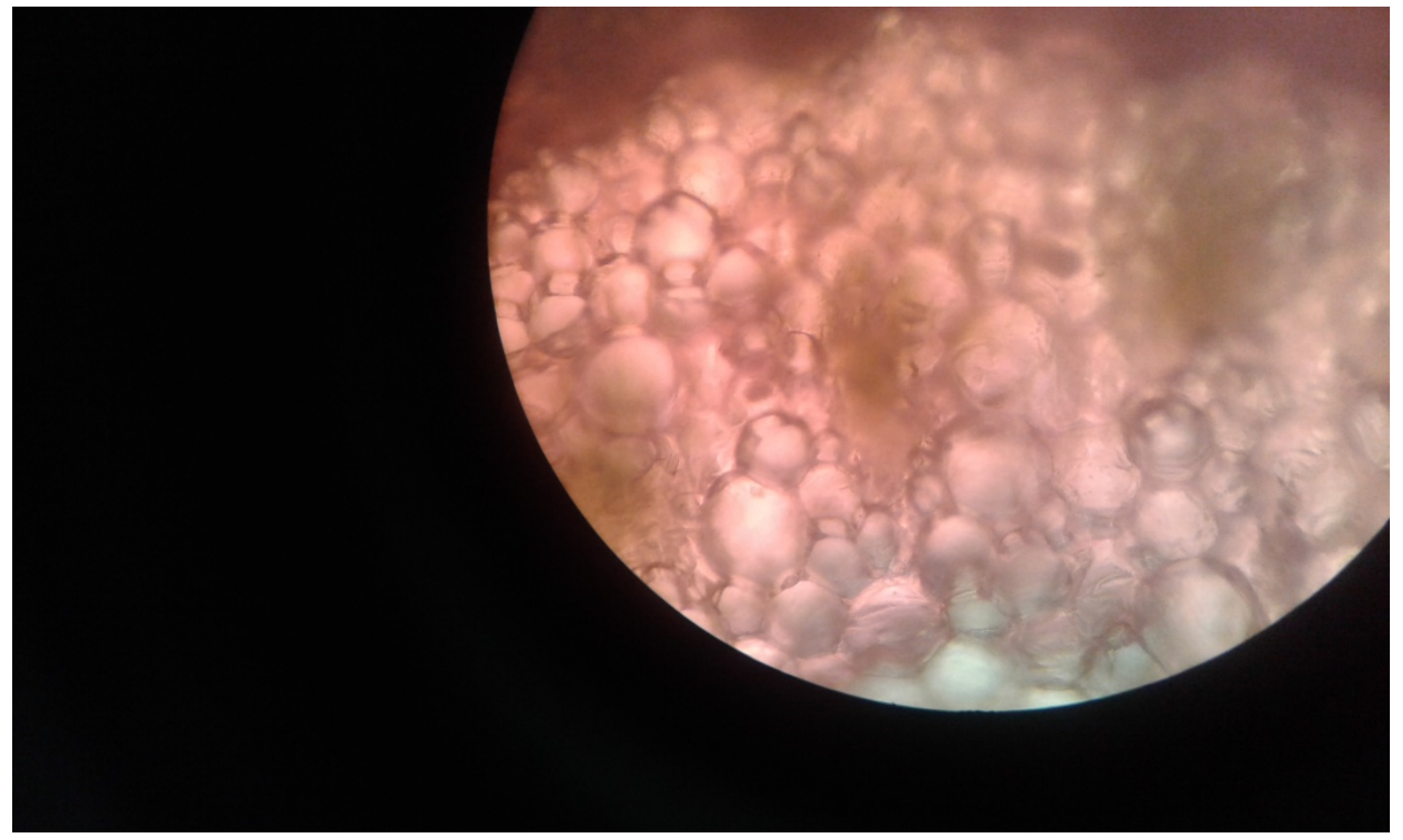

Figure 2. Showing a free hand section of Amaranthus species 
White blood cells and platelets did not stain with the acidified ethanol extracts of Bougainvillea $X$ buttiana bracts. All nuclei of white blood cells did not stain because they are acidic Granules of neutrophils and basophils are acidicand so they could not stain with acidified ethanol extracts of Bougainvillea $X$ buttiana. The cytoplasm of monocytes and lymphocytes are acidic and could not stain with acidified ethanol extracts of Bougainvillea X buttiana. Most importantly, failure to stain nuclei made it even harder to see white blood cells and also to scrutinize their features which stain with acidic dyes such as the granules of eosinophils which stain red with the acidic component of Romanowsky stains and the cytoplasm of neutrophils which also stains pale pink with the acidic component of Romanowsky stains (Cheesebrough et al., 2006). Red blood cells stained only with the extract prepared using $10 \mathrm{~g}$ of Bougainvillea X buttiana bracts powder and $100 \mathrm{ml}$ of acidified absolute ethanol when applied for 20 minutes and 30 minutes. The basic cytoplasm of the red blood cells (Cheesebrough et al.,2006) stained pink making the area of central pallor in red blood cells visible. For the case of stained freehand thin transverse stem sections of Amaranthus species using acidified ethanol extracts of Bougainvillea $X$ buttiana bracts, only extracts prepared using $5 \mathrm{~g}$ and $10 \mathrm{~g}$ of Bougainvillea $X$ buttiana bracts powder stained the specimen for all the staining durations which were tested. That is from 3 minutes to 27 minutes. This extract stained the cytoplasm pink. The cells of the cortex region stained lightly and appeared pale while the regions around vascular bundles and peripheral parts of the section stained strongly which is a similar pattern of staining observed by Deepali et al., (2014) when they stained Hibiscus stem sections with extracts of Bougainvillea glabra. Cell walls and intercellular spaces were visible and also vascular bundles appeared as tiny groups of colorless or unstained lacunae.

\section{CONCLUSIONS AND RECOMMENDATIONS}

This study shows that acidified ethanol extracts of Bougainvillea $X$ buttiana can be used in laboratory staining procedures to stain cells. Acidified methanol extracts of Bougainvillea X buttiana were unsuccessful when applied as simple positive stains for Staphylococcus aureus and Escherichia coli. In thick films of human blood, granules of eosinophils and cytoplasm of neutrophils appeared not to stain with the extracts. Red blood cells of thin films of human bloodstained when extracts prepared with $100 \mathrm{ml}$ of acidified absolute ethanol and $10 \mathrm{~g}$ of Bougainvillea X buttiana bracts powder were applied for 20 minutes and 30 minutes. Thin free hand sections of stems of Amaranthus species stained more successfully compared to other specimens. Effective staining of Amaranthus species was achieved when extracts prepared with 100 $\mathrm{ml}$ of acidified $50 \%$ ethanol and $5 \mathrm{~g}$ and $10 \mathrm{~g}$ of Bougainvillea $\mathrm{X}$ buttiana bracts powder and when extracts prepared with $100 \mathrm{ml}$ of acidified absolute ethanol and $10 \mathrm{~g}$ Bougainvillea $\mathrm{X}$ buttiana bracts powder.

\section{Recommendations}

- Acidified ethanol extracts of Bougainvillea X buttiana should be tried in negative staining technique for Staphylococcus aureus and Escherichia coli since they did not stain when applied as positive stains.

- A basic dye should be tried along with the acidified ethanol extracts of Bougainvillea X buttiana to enhance the vision of granules of eosinophils and cytoplasmic components of neutrophils.

- Stems of Amaranthus species should be processed using a histokinette and sectioned using a microtome for better sections which can easily be preserved.

- Giemsa stain should be used to prepare controls of blood films.

\section{Acknowledgement}

The efforts of Penyuthi Vonrick are recognized for the assistance he provided during the study. The effort of researchers who did studies in similar fields cannot remain unnoticed in this cause. Last but not least I extend my gratitude to authors, editors and publishers of all those articles and books from where the literature for this study has been reviewed and discussed.

Special thanks to Mr. Kizito Muwonge and Mr. William Muyombya for the good supervisory work during the research project.

I thank the medical editor, Mr. David Serunjogi for having improved this work for publication. 


\section{References:}

1. Cheesebrough, M. (2006). District laboratory practice in tropical countries (2nd ed). New York: Cambridge University Press. 36-38, 43, 319-322.

2. Cheesebrough, M. (2009). District laboratory practice in tropical countries (2nd ed). New York: Cambridge University Press. 247-248.

3. Deepali, K., Lalita, S., \& Deepika, M. (2014). Application of aqueous plant extracts as biological stains. International journal of scientific and engineering research, 5(2), 1586-1589.

4. Delgado-Vargas, F., Jimenez, A. R., \& Paredes-Lopez, O. (2000). Natural pigments: Carotenoids, anthocyanins, and betalain - characteristics, biosynthesis, processing, and stability. Critical reviews in food science and nutrition, 40(3), 173-289.

5. Handa, S. S., Khanuja, S. P. S., Longo, G., \& Rakesh, D. D. (Eds.). (2008). Extraction technologies for medicinal and aromatic plants. Trieste: United Nations Industrial Development Organization and International Centre for Science and High Technology. p 22.

6. Ihuma, J., Asenge, G., Abioye, K., \& Dick, S. (2012). Application of methanolic extracts from Hibiscus sabdariffa line as a biological staining agent for some fungal species, International journal of plant, animal and environmental science, 2(3), 543-549.

7. Ratna \& Padhi, B.S. (2012). Pollution due to synthetic dyes toxicity and carcinogenicity studies and remediation. International journal of environmental sciences, 3(3), 940-947.

8. Sabarudin, N. A., Munaim, M. S. A., Ab, Z \& Wahid. (2016). Effect of extraction condition of natural dye pigment from Bougainvillea flower's bract. Australian journal of basic and applied sciences, 10(17), 172-175.

9. Talaro, K. P., \& Talaro, A. (2002). Foundations in microbiology (4th ed). New York: Mc Graw Hill. 80-82

10. Raheem Esam M. A. Abd-Alhafeez Osman Ibnouf. Osman H. S.Hamza JM. F. (2015). “Using of Hibiscus Sabdariffaextract as a natural histological stain of the Skin." American journal of scientific communication. 